\title{
Perancangan Media Informasi Mengenai Hewan Reptil Chameleon Dalam Buku Ensiklopedia
}

\author{
Savira Alvina Syakur ${ }^{1}$, Taufan Hidayatullah ${ }^{2}$ \\ ${ }^{I}$ Desain Komunikasi Visual, Fakultas Desain, Universitas Komputer Indonesia, Bandung \\ ${ }^{2}$ Magister Desain, Fakultas Desain, Universitas Komputer Indonesia, Bandung \\ Email: ${ }^{1}$ saviraalvina5@gmail.com, ${ }^{2}$ taufan.hidayatullah@email.unikom.ac.id
}

\begin{abstract}
Abstrak: Perancangan dari salah satu hewan reptil mulai dari bentuk dan kemampuannya, hewan reptil tersebut ialah Chameleon. Hewan ini banyak yang belum memahami mengenai bentuk juga dari karakteristiknya. Adapun yang menjadikan latar belakang dari perancangan ini karena hewan Chameleon ini memiliki daya tariknya sendiri mulai dari kemampuannya yang dapat merubah warnanya dan juga sebagai hewan peliharaan yang jinak dan juga memiliki sebuah nilai dilingkungan sosial, hewan Chameleon ini merupakan hewan impor. Chameleon merupakan hewan yang mempunyai pecintanya sendiri namun banyak juga yang menganggap bahwa Chameleon merupakan hewan yang kurang tepat untuk dipelihara. Oleh karena itu, penting untuk adanya sebuah media informasi yang didalamnya terdapat pemaparan tentang hewan Chameleon adalah hewan yang mengagumkan dan cara pemeliharaan Chameleon dengan menggunakan bahasa yang sederhana dan mudah dimengerti agar kegiatan memelihara Chameleon di masyarakat bukan lagi kegiatan yang sulit untuk dikerjakan. Solusi perancangan yang akan dibuat ialah dengan menghadirkannya sebuah media informasi mengenai hewan reptil Chameleon yaitu sebuah buku ensiklopedia yang memaparkan jelas mulai dari jenis Chameleon hingga cara memelihara Chameleon.
\end{abstract}

Kata kunci: buku, Chameleon, ensiklopedia, informasi, reptil.

Abstract: The design of one of the reptile animals starting from its shape and ability, the reptile animal is Chameleon. Many of these animals do not understand the shape as well as its characteristics. As for what makes the background of this design because this Chameleon animal has its own charm, starting from its ability to change its color and also as a tame pet and also has a value in the social environment, this Chameleon animal is an imported animal. Chameleon is an animal that has its own love, but many also think that Chameleon is an animal that is not right to be kept. Therefore, it is important for an information medium in which there is a description of Chameleon animals which are amazing animals and how to keep Chameleon using simple and easy to understand language so that keeping Chameleon in the community is no longer a difficult activity to do. The design solution that will be made is to present an information media about Chameleon reptiles, which is an encyclopedia book that clearly explains the types of Chameleon to how to care for Chameleon.

Keywords: books, Chameleon, encyclopedia, information, reptiles.

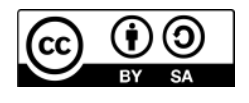




\section{PENDAHULUAN}

Hewan peliharaan merupakan hewan yang hidup berdampingan dengan manusia atau merupakan bagian dari keseharian masyarakat. Hewan peliharaan di masyarakat banyak sekali jenisnya, akan tetapi yang biasa ditemukan dan juga diketahui oleh masyarakat hanya beberapa jenis hewan yang umum saja seperti anjing, kucing, ikan, kura - kura dan masih banyak lagi. Masyarakat kurang tertarik dengan hewan endemic karena masyarakat khawatir apakah hewan tersebut aman atau tidak untuk dipelihara (Susanto, 2015) [1].

Sebelum memutuskan untuk memelihara hewan masyarakat harus mengetahui terlebih dahulu tahapan- tahapan atau syarat untuk dapat memelihara hewan, karena memelihara hewan bukan suatu hal yang mudah karena masyarakat harus memperhatikan juga kesejahteraan hewan tersebut. Terdapat lembaga yang menangani perihal kesejahteraan hewan, yaitu lembaga yang telah mengatur sebuah kebijakan mengenai hewan yang dapat dipelihara dan hewan yang tidak dapat dipelihara atau hewan yang dikategorikan oleh hukum CITES (Convention on International Trade in Endangered Spesies of Wild Fauna and Floral).

Chameleon merupakan hewan endemic dari madagaskar yang dimana terdapat 150 spesies Chameleon di dunia termasuk subfamili, bunglon khas (Chamaeleoninae) dan bunglon kerdil (Brookesiinae). Dengan warnanya yang menarik dan juga kemampuannya yang dapat merubah warna ini merupakan sebuah nilai jual bagi Chameleon. Banyak yang berminat untuk memelihara ataupun untuk menternakan Chameleon, di Indonesia sendiri Chameleon sudah memiliki pecintanya banyak komunitas-komunitas yang memelihara Chameleon. Terdapat beragam faktor Chameleon dipilih sebagai binatang peliharaan yang pertama adalah gengsi, karena harganya yang cukup mahal yaitu Chameleon yang baru berusia 3-4 bulan saja harganya mencapai 2,5-4 jutaan. Faktor yang lain yaitu Chameleon merupakan hewan yang tergolong jinak karena Chameleon bergerak lambat dan tidak membahayakan.

Hewan peliharaan beragam jenisnya dan juga sesuai dengan minat atau kesukaan dari pemiliknya. Chameleon merupakan hewan peliharaan yang tergolong tidak wajar atau jarang sekali orang pelihara dikarenakan Chameleon berasal dari keluarga hewan reptil. Hewan reptil adalah hewan yang vertebrata atau bertulang belakang dan juga hewan yang berdarah dingin. Memiliki sisik ditubuhnya seperti ular, buaya, kura-kura, kadal dan banyak lagi. Hewan reptil memiliki habitat asli yang kebanyakan di darat dan di perairan, namun ada juga golongan hewan reptil yang dan dapat hidup di kedua habitat tersebut yaitu bisa hidup di dua alam yaitu di perairan dan darat (Desi Wulandari, 2018) [2].

Chameleon merupakan hewan endemic dari Madagascar disana terdapat lebih dari 150 spesies yang ada di dunia termasuk juga sekitar 60 spesies Chameleon yang tidak dapat di temukan di tempat lain. Chameleon termasuk hewan reptil, familia dengan reptil kadal. Chameleon merupakan hewan yang terkenal akan kemampuannya untuk merubah warnanya. Di Indonesia disebut juga sebagai bunglon yang berasal dari Famili Agamidae atau Genus Calotes. Meskipun bunglon 
sama-sama dapat merubah warnanya namun bunglon berbeda dengan Chameleon dalam berbagai hal. Banyak yang keliru mengenai perbedaan antara Chameleon, bunglon dan juga iguana. Jika dilihat dari bentuk fisiknya ketiganya memiliki bentuk yang serupa namun beberapa spesifikasi fisiknya dan juga kemampuannya berbeda-beda satu sama lainnya.

Chameleon sangat terkenal dengan kemampuannya dalam merubah warna tubuhnya, kemampuan berubah warnanya Chameleon ini berbeda dengan bunglon yang dimana bunglon merubah warnanya karena menghindari dari mangsanya dengan merubah warna tubuhnya sama dengan lingkungan sekitarnya. Berbeda halnya Chameleon akan merubah warnanya menjadi lebih gelap ketika suhu menjadi lebih dingin. Jika Chameleon sedang marah atau sedang ditantang oleh jantan lain maka Chameleon akan merubah warnanya menjadi merah kekuningan. Jika datang musim kawin maka Chameleon akan merubah warnanya menjadi warna warna yang terang untuk menarik lawan jenisnya (Matondang, 2013) [3].

Menurut Sumadewa (2020, dalam Yunizarrakha dkk.,) kemampuan Chameleon dalam merubah warnanya ini disebut sebagai mimikri "pemiripan" atau peniruan secara fisik ataupun perilaku [4]. Perubahan warna Chameleon disebabkan karena adanya sel-sel khusus yang terdapat dilapisan kulit Chameleon sel ini disebut sebagai chromataphores. Chromataphores adalah sebuah sel yang terdapat pada lapisan bawah kulit terluar dari Chameleon yang terkait erat satu dengan yang lainnya. Adapun pigmen warna melanin yang mengatur perubahan dari warna Chameleon. Bentuknya menyerupai serat yang terdapat pada jaring laba-laba yang menyebar melalui lapisan sel chromatophores. Proses terjadinya perubahan warna pada Chameleon ini berawal dari ketika mata Chameleon menangkap rangsang warna/tekanan/perubahan suhu/birahi(musim kawin) dari lingkungan sekitarnya. Setelah rangsangan diterima kemudian disalurkan ke bagian epitalamus.

Perubahan warna Chameleon dimulai dengan ketika mata yang mengamati lingkungan sekitarnya lalu direspon melalui mata dan disampaikan ke otak, dari otak menggerakkan otot-otot chromatophore sehingga terjadinya perubahan warna kulit yang menyerupai warna sekitar (Pasla, 2016) [5].

\section{METODE}

Pada perancangan media informasi ini, perancang menggunakan metode studi kasus terhadap yang pencinta hewan dan yang tidak suka dengan hewan untuk melihatnya wawasan masyarakat terhadap hewan peliharaan sebelum lebih memahaminya objek dari perancangan ini. Oleh karena itu, metode ini perlu adanya merancang strategi komunikasi dan strategi kreatif, metode ini agar pesan dapat tersampaikan dengan baik sehingga tidak adanya kesalahpahaman atau kekeliruan di masyarakat. 
Strategi komunikasi yang dibuat dalam perancangan informasi ini ialah menggunakan bahasa Indonesia, hal ini dilakukan demi menjangkau dari khalayak sasaran yang tersebar di kota-kota besar yang ada di Indonesia. Strategi komunikasi yang dirancang agar khalayak sasaran terdorong terlebih dahulu tertarik untuk mengetahui mengenai hewan Chameleon.

Sedangkan, untuk strategi kreatif yang digunakan pada media dibuat dengan semenarik mungkin dengan ilustrasi hewan Chameleon yang menarik dengan penuh warna yang unik juga.

\section{Objek Penelitian}

Untuk objek penelitian ini akan terfokus pada beberapa hal mengenai Chameleon, yaitu mulai asal dari Chameleon, keluarga Chameleon, jenis-jenis Chameleon yang biasa dipelihata di Indonesia, cara perawatan Chameleon, hal apa saja yang bisa membahayakan Chameleon dan yang terakhir mengenai cara mengimpor Chameleon ke Indonesia.

\section{Prosedur Pengambilan Data}

Untuk mencari referensi mengenai hewan Chameleon, perancang melakukan studi literatur berupa buku, artikel dan juga jurnal-jurnal online. Selain itu perancang mencari sumber informasi lain dengan menggunakan media-media online seperti pada video Youtube mengenai Chameleon.

Selain pencarian referensi berupa studi literatur, perancang juga memperkuat referensinya dengan menyebarkan kuisioner kepada khalayak sasaran untuk mengetahui pemahaman masyarakat terlebih dahulu mengenai hewan Chameleon.

\section{Tahapan Pembedahan Objek Penelitian}

Setelah sumber referensi-referensi untuk memperoleh data-data mengenai Chameleon ini, maka tahapan selanjutnya yaitu menyusun informasi, strategi komunikasi dan strategi kreatif. Hasil dari studi literatur yang akan dijadikan sumber data-data untuk informasi dalam perancangan hewan Chameleon untuk media informasi khalayak sasaran.

Sedangkan untuk kuesioner bertujuan untuk melihat permasalahan apa yang ada di masyarakat dan sebagai acuan bagi perancang apa saja yang ingin disampaikan kepada khalayak sasaran agar media yang nantinya akan dibuat pesannya akan tersampaikan dengan baik dan dapat memecahkan masalah-masalah yang ada pada pengumpulan data kuisioner tersebut. 


\section{Metode Analisa}

\section{Target Audiens}

Sebelum merancang sesuatu perlu diketahui khalayak sasarannya terlebih dahulu, karena dalam sebuah perancangan harus mengetahui subjek yang nantinya akan dijadikan sasaran atau tujuan dalam sebuah penyampaian informasi sehingga terjadinya proses komunikasi. Penentuan khalayak sasaran ini adalah untuk memastikan tujuan telah tercapai (obtained effect) (Hamad, I. 2014) [6]. Oleh karena itu, target audiens yang dipilih adalah dewasa awal dengan rentang usia 2040 tahun, dan pada target audiens ini memiliki status ekonomi dikalangan menengah atas hingga kalangan atas yang tersebar di kota kota besar di Indonesia.

Selain faktor di atas, perancang juga menargetkan pada target audiens yang memiliki ketertarikan atau memiliki minat terhadap hewan peliharaan atau memiliki hobi dalam merawat atau memelihara hewan, dan memiliki tanggung jawab akan berkomitmen menjaga hewan tersebut. Adapun jenis kelamin yang dijadikan target audiens pada perancangan media informasi Chameleon ini ialah perempuan dan laki-laki, walau demikian mayoritas merupakan berasal dari lakilaki tapi tidak menutup kemungkinan perempuan pun banyak yang menyukai hewan reptil.

Hal ini merupakan sebuah hal yang wajar bahwa kebanyakan merupakan mayoritas dari kaum laki-laki, dikarenakan adanya budaya patriarki budaya patriarki ini merupakan sebuah konsep yang mengacu pada suatu kondisi dimana segala sesuatu diterima secara fundamental dan juga universal didominasi oleh kaum laki-laki (Hidayatullah, 2011) [7].

\section{Tujuan dan Pendekatan Komunikasi}

Sebelum melakukan perancangan sebuah media informasi hal ini dirasa sangat penting yang dimana tujuan komunikasi ini ialah agar pesan dapat tersampaikan dengan baik. Sebuah komunikasi ini merupakan kegiatan interaksi antara individu yang satu dengan individu yang lainnya. Sedangkan tujuan dari komunikasi itu sendiri ialah saling memahaminya atau ada pengertian bersama antara yang memberi pesan dan yang menerima pesan. Dalam menentukan tujuan komunikasi terdapat hal-hal yang harus diperhatikan antara lain 1) harus memperhatikan tanggapan/efek, 2) memahami khalayak sasaran, 3) harus dapat menggerakan khalayak sasaran (Nurohim, 2009) [8].

Adapun tujuan komunikasi dari perancangannya media informasi mengenai Chameleon dan cara pemeliharaannya ialah agar masyarakat atau khalayak sasaran bisa lebih memahami mengenai hewan Chameleon dan memberi informasi kepada khalayak sasaran yang hendak memelihara Chameleon untuk mengetahui bagaimana cara memelihara Chameleon yang baik dan benar supaya meminimalisir terjadinya kesalahan dalam memelihara Chameleon dan potensi Chameleon tidak mudah mati. 


\section{Mandatory}

Mandatory disini memiliki fungsi sebagai lembaga atau pihak yang berhak untuk menyebarluaskan atau mendistribusi dari media yang nanti akan digarap. Media informasi mengenai Chameleon ini merupakan sebuah buku ensiklopedia beserta media lainnya oleh karena itu mandatory yang akan dipilih ialah Gramedia.

Gramedia merupakan sebuah toko buku yang tersebar di kota-kota besar di Indonesia oleh karena itu akan memudahkan bagi khalayak sasaran untuk menjumpai media informasi ini. Bahkan dalam satu kota besar yang ada di Indonesia saja dapat dijumpai beberapa store gramedia. Perusahaan yang telah berdiri sejak 2 februari 1970 ini sudah terdapat 50 toko yang tersebar di seluruh wilayah Indonesia.

\section{Strategi Kreatif dan Media}

Strategi kreatif menggunakan gaya bahasa. Dalam gaya bahasa ini merupakan sebuah cara dari seseorang untuk menyampaikan sebuah pesan atau informasi. Gaya bahasa menurut (Ali Imron Al-Ma'ruf, 2010) [9] gaya bahasa ini sangat berkaitan dengan selera pengarangnya dan juga kepekaan terhadap suatu masalah yang ada di lingkungannya. Adapun Gaya yang akan digunakan pada pembuatan media informasi ini ialah menggunakan gaya bahasa eksposisi. Gaya eksposisi adalah suatu bentuk tulisan atau suatu retorika yang di dalamnya menguraikan pokok pikiran guna memperluas pandangan atau pengetahuan pembaca menurut (Farel Olva Zuve, 2016) [10].

Strategi kreatif ini perlu dilakukan dalam perancangan sebuah media. Hal ini karena dalam perancangan buku ensiklopedia harus memikirkan juga agar khalayak sasaran atau masyarakat tertarik akan Chameleon terlebih dahulu yang kemudian nantinya akan tertarik untuk membaca, untuk itu diperlukannya langkah-langkah kreatif untuk menarik perhatian khalayak sasaran atau pun masyarakat. Dan strategi kreatif ini memiliki tujuan agar pesan yang ingin disampaikan kepada khalayak sasaran atau masyarakat dapat tersampaikan dengan baik dan tidak adanya kekeliruan atau kesalah pahaman dalam penyampaiannya.

\section{Copywriting}

Copywriting dalam sebuah perancangan media merupakan tahapan yang penting selain tahapan visual. Copywriting ini bisa menjadi penentu dari khalayak sasaran atau masyarakat tertarik atau tidaknya untuk membaca sebuah media informasi. Biasanya buku akan memuat judul semenarik mungkin sehingga membuat si pembaca menjadi penasaran untuk membaca.

Headline untuk media informasi ini adalah 'Chameleon Cyclopedia'. Headline ini diambil agar memudahkan khalayak sasaran untuk mencari media informasi ini 
sendiri seperti langsung melihat judulnya sudah mengetahui apa isi dari media informasi ini.

Tagline merupakan kata pendukung dari headline yang dimana menjelaskan atau mendeskripsikan secara singkat guna menarik khalayak sasaran. Tagline yang akan digunakan pada media informasi ini adalah: "Cara pemeliharaan". Tagline tersebut memiliki arti dari inti media informasi ini yang memudahkan target audiens yang ingin memelihara Chameleon namun kekurangan informasi akan cara pemeliharaan Chameleon itu sendiri.

\section{Rancangan Visual}

Dalam visualisasi perancangan media buku ensiklopedia ini terinspirasi dari buku buku yang sudah ada namun ada beberapa referensi dari mulai tata letak ilustrasi, kemudian tata letak dari penjelasan perbagian. Sebagian besar layout akan terinspirasi dari buku-buku National Geographic. Namun dalam perancangan media informasi ini akan disajikan dalam bentuk ilustrasi.

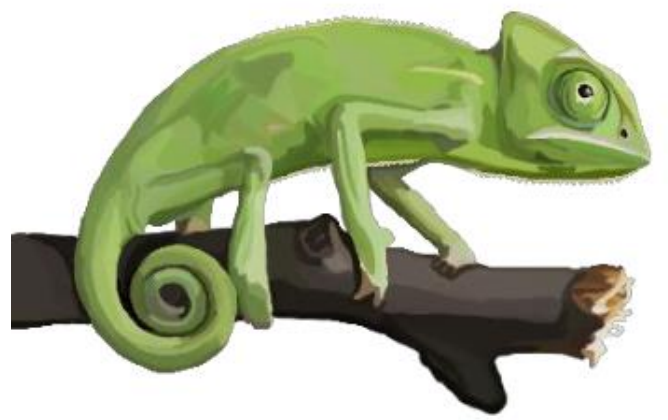

Gambar 1. Contoh ilustrasi yang digunakan Sumber: Dokumen Pribadi (2020)

\section{HASIL DAN PEMBAHASAN}

Dalam konsep visual terdapat konsep yang tersusun dengan sangat baik dan dikemas sedemikian menarik perhatian khalayak sasaran. Konsep visual ini biasanya terdiri dari sebuah pemikiran, ide atau gagasan visual nanti yang akan digarap. Adapun yang termasuk dalam konsep visual disini yang perlu diperhatikan antara lain seperti format desain, layout atau tata letak, tipografi, dan yang paling penting ialah warna.

Untuk media informasi sebagian besar layout akan terinspirasi dari buku-buku National Geographic. Mulai dari cover yang di desain sedemikian rupa sangat menarik namun dengan layout yang simple dapat menarik pembaca untuk membelinya, selain itu National Geographic yang sebelumnya disebut sebagai National Geographic Magazine adalah sebuah majalah resmi dari National Geographic Society. 


\section{Format Desain}

Format desain yang berisikan gambar dan juga narasi dan terkombinasi secara simultan dan juga memberikannya kontribusi secara positif terhadap khalayak sasaran atau pemeroleh informasi (Munawaroh, 2010) [11]. Karya yang nanti akan di gambar akan menggunakan resolusi 300 dpi karena gambar yang akan dibuat menggunakan gaya realis maka perlu resolusi yang tinggi untuk memperjelas detail detail terutama pada media yang kecil detail tersebut sangat penting seperti warna tekstur agar tidak terjadinya kesalah pahaman dalam menerima informasi. Media informasi yang akan dibuat ialah buku ensiklopedia yang berukuran A4 atau 21,0 x $29,7 \mathrm{~cm}$ dan dalam bentuk potrait.

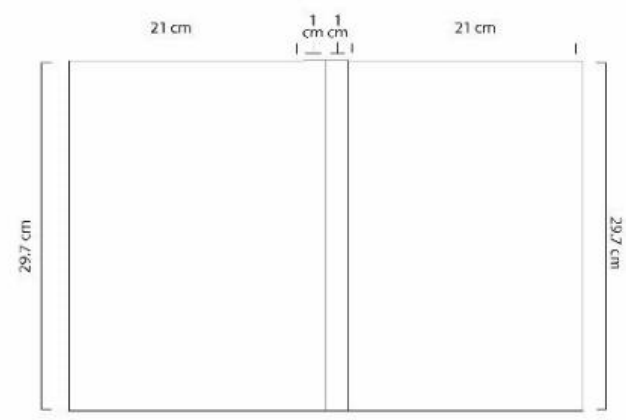

Gambar 2. Sketsa format desain Sumber: Dokumentasi Penulis (2020)

\section{Tata Letak}

Media utama pada media informasi ini dirancang dengan tata letak antara halaman satu dengan yang lainnya berhubungan. Dengan juga menggunakan penataan teks, ilustrasi dan dekorasi yang saling berhubungan satu sama lainnya.

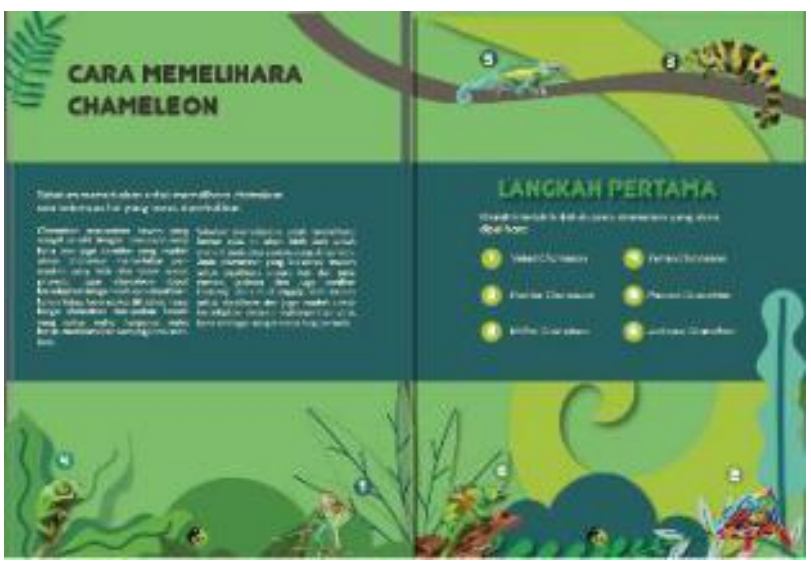

Gambar 3. Tata letak media utama Sumber: Dokumentasi Penulis (2020) 


\section{Tipografi}

Tipografi merupakan salah satu ilmu dari desain komunikasi visual yang biasa dikatakan sebagai "visual language" yang memiliki makna bahasa yang dapat dilihat atau dinikmati menurut (Priscilia Yunita Wijaya, 1999) [12]. Pentingnya dari tipografi dalam desain ialah untuk menjadikan desain tersebut mudah dipahami dan dapat dimaknai dengan benar sehingga tidak terjadinya kekeliruan akan persepsi atau pandangan khalayak terhadap sebuah desain. Tipografi ini sering dijumpai di kehidupan sehari-hari seperti poster yang terdapat di jalan, stiker yang terdapat di helm, banner yang ada di tempat-tempat umum. Dalam perancangan media ini akan menggunakan font junegull.

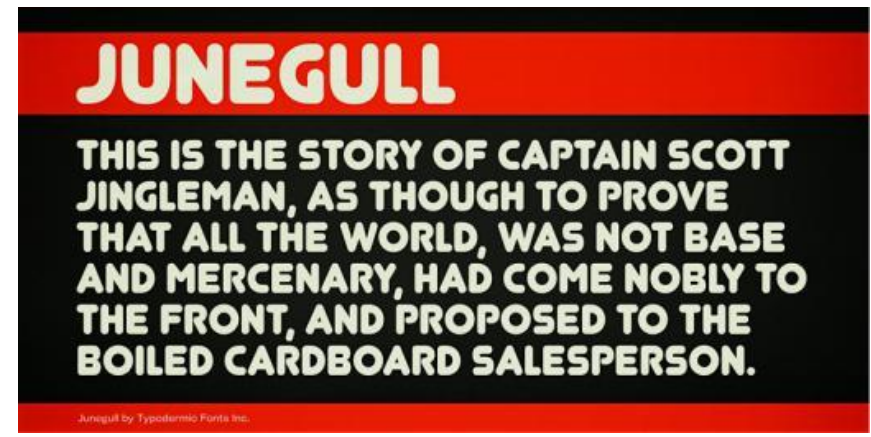

Gambar 4. Font Junegull

Sumber: http://www.dafont.com/ (2020)

Ini merupakan font yang biasa digunakan untuk judul untuk media buku ensiklopedia. Font ini sangat mudah di-download dan gratis digunakan karena font ini $100 \%$ free. Font ini memberikan kesan simple atau sederhana menarik dan selaras dengan halnya Chameleon ini.

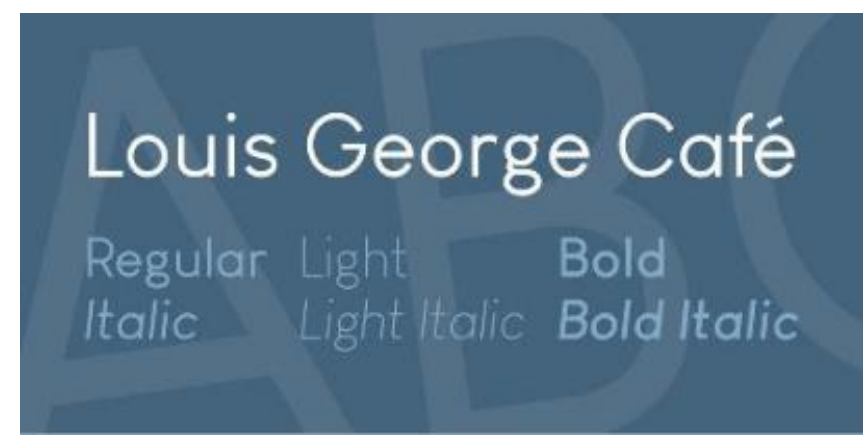

Gambar 5. Font Louis George Cafe Sumber: http://www.1001font.com/ (2020)

Sedangkan untuk body text akan menggunakan font Louis George Cafe. Font ini memiliki tingkat keterbacaannya jelas dan juga memiliki keluarga font yang cukup lengkap dan font ini merupakan font $100 \%$ free sehingga memudahkan perancang dalam melakukan perancangan buku ensiklopedia. 


\section{Warna}

Warna merupakan suatu unsur desain yang sangat penting dikarenakan dengan adanya warna sebuah karya atau desain akan lebih memberikan kesan dan pesan yang ingin disampaikan akan lebih mudah dipahami. Warna juga dapat membuat rangsangan beragam emosi. Maka dari itu, warna yang dipilih untuk media informasi ini adalah sebagai berikut:

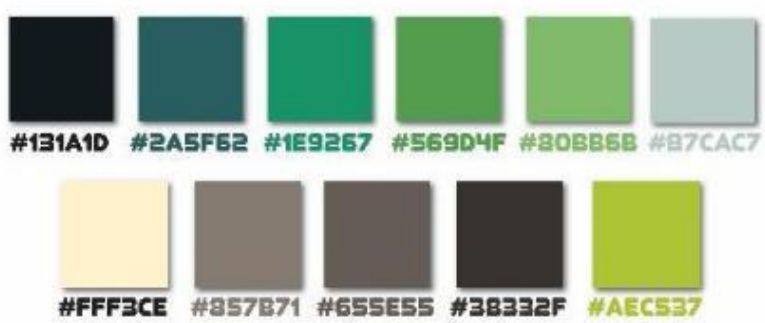

Gambar 6. Palet Warna Chameleon Sumber: Dokumentasi Penulis (2020)

Pada Gambar 6 merupakan beragam warna yang biasanya digunakan dalam warnawarna Chameleon oleh karena itu perancangan buku ensiklopedia beserta media pendukung yang nanti akan digarap akan menggunakan warna warna tersebut baik warna untuk tipografi sebagai judul ataupun menjadi background.

\section{Ilustrasi}

Menurut Maharsi (2016, h.9), ilustrasi adalah sebuah representasi atau gambaran dari kehidupan manusia yang penuh lika-likunya. Ilustrasi ini memiliki tujuan sebagai gambar yang berfungsi untuk menjelaskan atau mendeskripsikan sesuatu. Ilustrasi yang akan digarap akan menampilkan visual-visual yang realis. Pembuatan ilustrasi ini akan menggunakan teknik digital painting dan menggunakan software Adobe Photoshop. Pada Gambar 8 ini merupakan hasil ilustrasi dari referensi berupa foto Chameleon yang diilustrasikan menggunakan Adobe Photoshop.

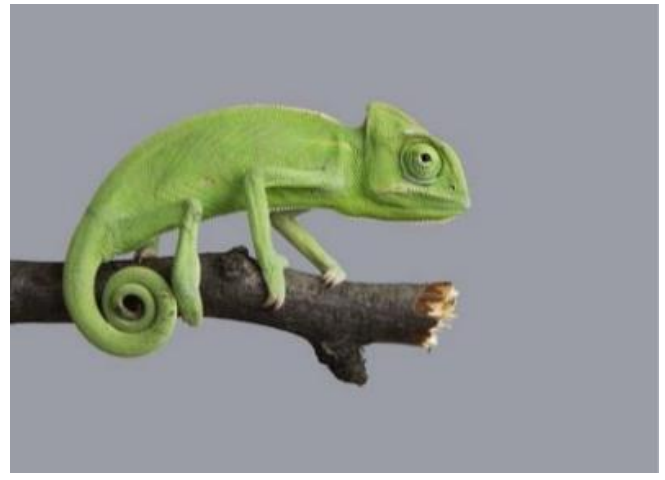

Gambar 7. Referensi Chameleon

Sumber: https://www.google.com/search?q=chameleon\&safe=strict\& (2020) 


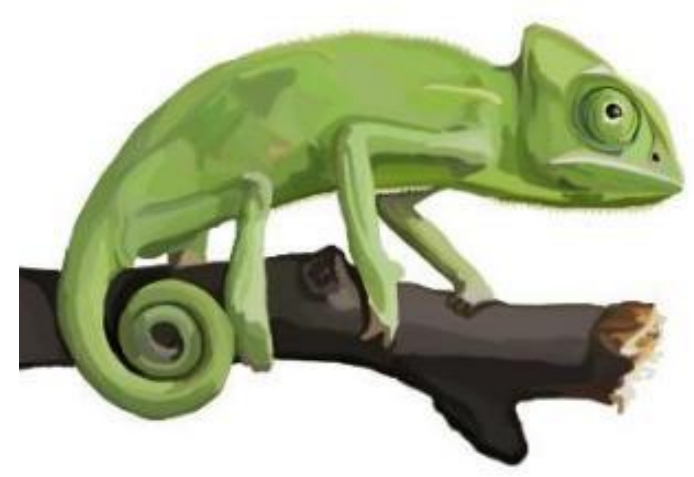

Gambar 8. Ilustrasi Chameleon Sumber: Dokumentasi Penulis (2020)

\section{Hasil}

Sebelum didistribusikan atau diterbitkan ke masyarakat media melalui rangkaian tahapan mulai dari pra-produksi, produksi sampai pasca produksi. Untuk proses distribusinya media utama ini akan diterbitkan di salah satu toko buku di Indonesia yaitu Gramedia, dengan mengadakan event.

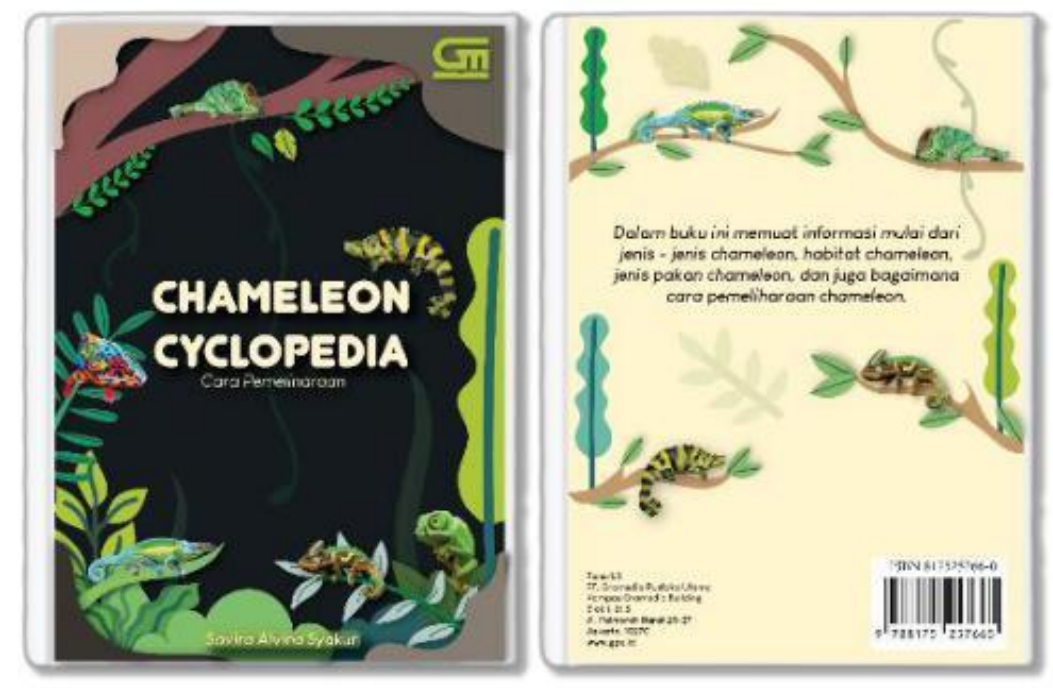

Gambar 9. Media Utama Ensiklopedia Chameleon Sumber: Dokumentasi Penulis (2020)

\section{Media Pendukung}

Banyak peran dalam media pendukung ini karena dengan adanya media pendukung media utama akan menjadi sukses. Dan media pendukung ini sebagai media pendamping media utama dan terdapat dua media pendukung yaitu media pendukung utama dan media pendukung merchandise. 


\section{1) Poster}

Menurut Icca Stella Amalia (2013) poster merupakan sebuah media gambar yang didalamnya terdapat unsur - unsur visual gambar, garis, dan terdapat kata kata yang tersusun untuk menarik perhatian dan agar dapat mengomunikasikan pesan secara singkat. [14] Poster ini dipilih menjadi media pendukung utama karena poster ini sebagai penarik perhatian dari khalayak sasaran atau tahap attention mengenai media informasi utama yaitu adanya buku ensiklopedia.

Pada Gambar10 ini merupakan poster pertama yang akan dipublikasikan. Poster ini akan dicetak berukuran A3 dengan bahan kertas art paper tebal yang dilaminasi doff, dan poster ini akan disebar di tembok jalan sekitaran perkantoran, kampus.

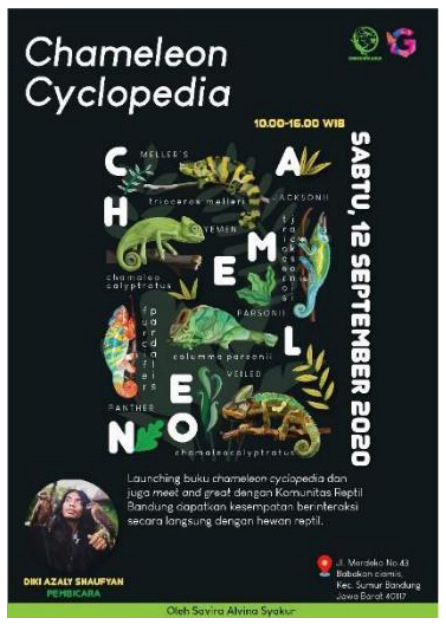

Gambar 10. Poster Promosi Buku Sumber: Dokumentasi Penulis (2020)

Poster pada Gambar 11 merupakan poster untuk penerbitan bukunya. Poster ini akan dicetak berukuran A3 dengan bahan kertas art paper tebal yang dilaminasi doff, dan poster ini akan disebar ditembok jalan sekitaran perkantoran, kampus.

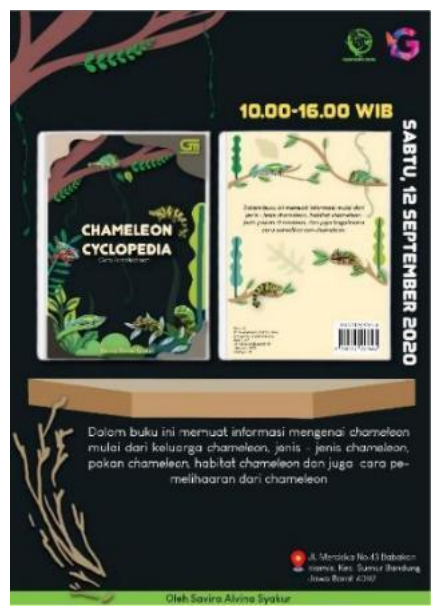

Gambar 11. Poster Launching Buku Sumber: Dokumentasi Penulis (2020) 


\section{2) Feed Instagram}

Feeds yang dibuat berjumlah 6 feeds, feeds Instagram ini berukuran $600 \times 600$ pixels dari masing-masing feed-nya, dan menggunakan warna RGB karena hanya disebarluaskan melalui digital.

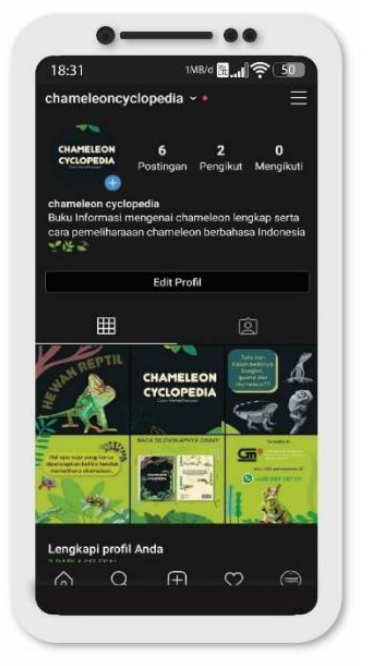

Gambar 12. Feed Instagram Sumber: Dokumentasi Penulis (2020)

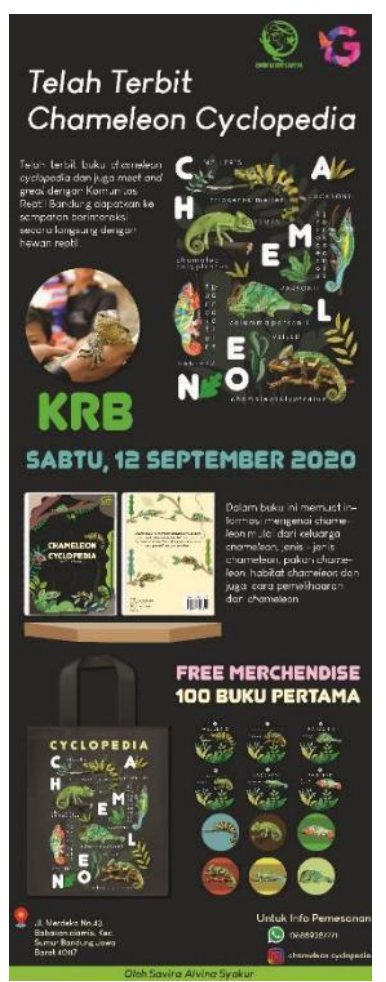

Gambar 13. X-Banner

Sumber: Dokumentasi Penulis (2020) 


\section{3) X-Banner}

$\mathrm{X}$-banner ini merupakan media pendukung utama lainnya dikarenakan di dalam Xbanner ini akan ada informasi mengenai media utama yaitu deskripsi singkat mengenai isi buku untuk membuat khalayak sasaran penasaran, kemudian terdapat waktu dan tempat terbitnya buku atau media utama dari Chameleon ini. Ukuran XBanner ini dibuat dengan $60 \times 160 \mathrm{~cm}$ yang diproduksi dengan cara digital printing, $\mathrm{x}$-banner ini menggunakan bahan luster.

\section{4) Totebag}

Totebag ini sangat bermanfaat bagi khalayak sasaran bisa digunakan dalam seharihari, totebag yang dirancang dengan visual Chameleon yang realis dan berwarna ini bisa dipakai untuk bergaya. Totebag yang berukuran $30 \mathrm{~cm}$ x $30 \mathrm{~cm}$ dan berbahan canvas.

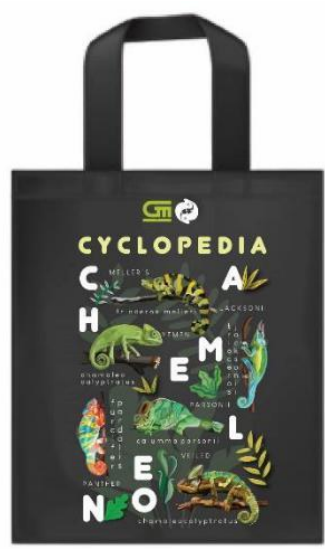

Gambar 14. Totebag

Sumber: Dokumentasi Penulis (2020)

\section{5) Gantungan Kunci}

Media pendukung gantungan ini dibuat sebagai pengingat dari media utama, gantungan ini bermanfaat dalam keseharian khalayak sasaran seperti menggunakan gantungan ini pada kunci kendaraan, kunci rumah, kunci kantor dan sebagainya, atau bisa juga menjadi aksesoris bada tas khalayak sasaran.

6) T-shirt

Kaos ini guna sebagai media pengingat yang dimana kaos akan digunakan dalam keseharian dari khalayak sasaran baik dirumah ataupun di luar rumah dapat digunakan. Kaos yang akan terdapat visual Chameleon dan kata-kata yang merujuk pada media utama akan didesain sedemikian rupa agar dapat dipakai dalam keseharian dan digunakan sebagai pengingat. Kaos size $\mathrm{m}-1$ dengan bahan cutton combat 30s. 


\section{7) Vest/Rompi}

Vest atau rompi ini biasa digunakan sebagai pelindung dada atau bisa juga sebagai pelengkap dari outfit. Vest ini juga biasa digunakan oleh para pecinta reptil sebagai seragam ketika adanya pameran hewan-hewan reptil. Vest yang akan dibuat nanti akan terdapat patch yang berada di bagian dada dengan teknis bordir. Patch memiliki ukuran $5 \mathrm{~cm} \times 5 \mathrm{~cm}$.

\section{8) Stiker}

Stiker ini sebagai media pengingat yang bisa digunakan atau ditempelkan dimana saja. Stiker akan diberikan secara gratis pada tahap promosi dan akan dicetak dan juga dijual satu paket dengan penjualan buku ensiklopedia.

\section{9) Jam Dinding}

Jam dinding ini bisa menjadi media pendukung pengingat yang dimana ketika khalayak sasaran hendak melihat waktu pada jam dinding bisa mengingat dari objek atau media utama.

\section{0) Tempat Minum}

Tempat minum ini dekat hubungannya dengan khalayak sasaran yang dimana biasanya digunakan oleh orang-orang yang bekerja di luar rumah dan memerlukan asupan air yang cukup sehingga tempat minum ini bisa menjadi media pendukung sebagai pengingat dari media utama.

\section{KESIMPULAN}

Berdasarkan uraian penjelasan yang sudah dipaparkan di atas, maka kesimpulan yang dapat diambil dari perancangan media informasi ini adalah untuk memudahkan dari khalayak sasaran yang ingin mengetahui mengenai hewan reptil Chameleon dengan singkat namun jelas mulai dari asal, jenis hingga proses pemeliharaannya. Dan selain adanya media informasi mengenai Chameleon ini juga terdapat media media pendukung yang dapat mengingatkan atau memberitahu kepada khalayak sasaran mengenai hewan satu ini.

\section{DAFTAR PUSTAKA}

Al-Ma'ruf, A. I. (2009). Stilistika: Teori, Metode, dan Aplikasi Pengkajian Estetika Bahasa.

Amalia, I. S. (2013). Evaluasi media poster hipertensi pada pengunjung Puskesmas Talaga Kabupaten Majalengka. KEMAS: Jurnal Kesehatan Masyarakat, 9(1), 1-8.

Hamad, I. (2014). Perancangan Program Komunikasi

Hidayatullah, T. Diskursus Jender dalam "Kebudayaan itu Berkelamin-Komik Tentang Arahmaiani”. Visualita, 3(1), 266936. 
Maharsi, I. (2016). Ilustrasi. Dwi-Quantum.

Matondang, A. E., \& Hariadi, M. D. (2013). Penerapan Tema Mimikri Pada Desain Museum Perkembangan Musik Pop Indonesia. Jurnal Sains dan Seni ITS, 2(2), G102-G104.

Munawaroh, I. (2010). Desain Pesan Multimedia Pembelajaran dalam Teori Pemrosesan Informasi. Majalah Ilmiah Pembelajaran, 8(2).

Nurrohim, H., \& Anatan, L. (2009). Efektivitas komunikasi dalam organisasi. Jurnal Manajemen Maranatha, 8(2), 11-20.

Pasla, V. D., \& Tinangon, A. J. (2016). ARSITEKTUR MIMESIS. MEDIA MATRASAIN, 13(1), 47-55.

Sumadewa, N. Y. (2020). Animasi 3 Dimensi Proses Mimikri Bunglon. Jurnal SASAK: Desain Visual dan Komunikasi, 2(1), 43-50.

Susanto, W., \& Gandha, M. V. (2015). Pusat Edukasi Tentang Hewan Peliharaan Di Kelapa gading. Jurnal Kajian Teknologi, 11(1).

Wijaya, P. Y. (1999). Tipografi dalam desain komunikasi visual. Nirmana, 1(1).

Wulandari, D. Objektivasi Hewan Reptil Sebagai Hewan Peliharaan: (Studi Upaya Brc Mengkonstruksi Sosial Hewan Reptil Di Banyuwangi).

Zuve, F. O. (2017). Peningkatan Kemampuan Menulis Eksposisi Menggunakan Strategi Pembelajaran Kooperatif Group Investigation. Jurnal Pendidikan Rokania, 1(2), 6879. 